\title{
Transnasal Endoscopic Surgery in Retro-orbital Abscess
}

\author{
JS Thakur, NK Mohindroo, DR Sharma, Ripudaman Arora
}

\begin{abstract}
Introduction: Transnasal endoscopic approach is well established in the management of subperiosteal abscess but retro-orbital abscess is commonly treated by external surgical approach. There are only two articles published on endoscopic drainage of retro-orbital abscess. We present our experience in the management of retro-orbital abscesses by transnasal endoscopic surgery.
\end{abstract}

Methods: Retrospective case charts review. Three cases with retro-orbital abscess were drained with endoscopic approach in last 5 years.

Conclusion: Role of transnasal endoscopic surgery in superiorlateral located intraorbital abscesses could not be evaluated but presented case series will further open the doors for transnasal endoscopic surgery.

Keywords: Endoscopy, Orbit, Abscess, Sinus surgery.

How to cite this article: Thakur JS, Mohindroo NK, Sharma DR, Arora R. Transnasal Endoscopic Surgery in Retro-orbital Abscess. Clin Rhinol Int J 2012;5(1):14-16.

Source of support: Nil

Conflict of interest: None

\section{INTRODUCTION}

Eye is an important facial unit, and vision is one of the five senses (hearing/taste/smell/sight/touch). Eye is delicate organ and easily exposed to injury from external and surrounding areas. Orbital cellulitis is one of the dangerous conditions, where delay in the management can lead to loss of vision or even death. It is commonly caused by sinusitis, trauma, odontogenic infection, external ocular infection and local skin inflammation. It was Hirschmann in 1903 used modified Nitze cystoscope in nose/maxillary antrum through tooth socket and now endoscopy has revolutionized the management of nose and sinus surgery. Transnasal endoscopic orbital decompression was first performed in 1990 to 91 for exophthalmos. ${ }^{1,2}$ Now, this approach is popular in the management of subperiosteal abscess but retro-orbital abscess is commonly treated by external surgical approach. There are very few published articles on endoscopic drainage of retro-orbital abscess. ${ }^{3,4}$ We present our experience with transnasal endoscopic surgical (TNES) management of retro-orbital abscess.

\section{METHODS AND PATIENTS}

We reviewed case record of patients presented to us in last 5 years with orbital abscess. Three cases were found eligible for the objective of study.

\section{Patients}

There were three cases of orbital abscess referred from the ophthalmology department. Two cases had complicated sinusitis leading to orbital abscess, while third case sustained trauma in eye leading to abscess. All cases were started on intravenous antibiotics (Co-amoxiclav, ornidazole, gentamicin) and anti-inflammatory. High resolution CT scan (HRCT) or CT scan of nose and paranasal sinus (PNS) was obtained in all cases and patients were subjected to surgery under general anesthesia.

\section{Transnasal Endoscopic Surgery (TNES)}

Under general anesthesia, surgery was performed with $4 \mathrm{~mm} 0^{\circ}$ and $30^{\circ}$ rigid endoscopes. Lamina papyracea was exposed after removing uncinate process, bulla ethmoidalis, and ethmoid air cells. Lamina papyracea was gently broken with 'J' curette, and removed completely. Horizontal incision was made in the periorbita with sickle knife, and pus was drained after gentle and gradual external pressure on the eye globe. Ophthalmological examination was done as soon as patient became ambulatory to assess the surgical outcome or any complication.

\section{CASE REPORTS}

\section{Case 1}

A 27-year-old male was admitted in ophthalmology department with proptosis and pain in right eye for last 2 weeks. There was no other contributory history. General and systemic examination was insignificant. There was lateral proptosis with absent medial ocular movements (Fig. 1). Right eye visual acuity was decreased to 6/18, and fundus examination found macular edema. Patient was started on antibiotics and CT orbit found ethmoid opacification with retro-bulbar abscess (Fig. 2). Patient was referred to us for endoscopic drainage and orbital decompression, and $3 \mathrm{ml}$ thick pus was drained which came sterile after 24 hours incubation. Visual acuity improved to $6 / 9$ on postoperative day 1 . Patient had complete recovery of vision and ocular movements in next 7 days.

\section{Case 2}

A 4-year-old female child presented with swelling, redness, increased watering and inability to open left eye for last 


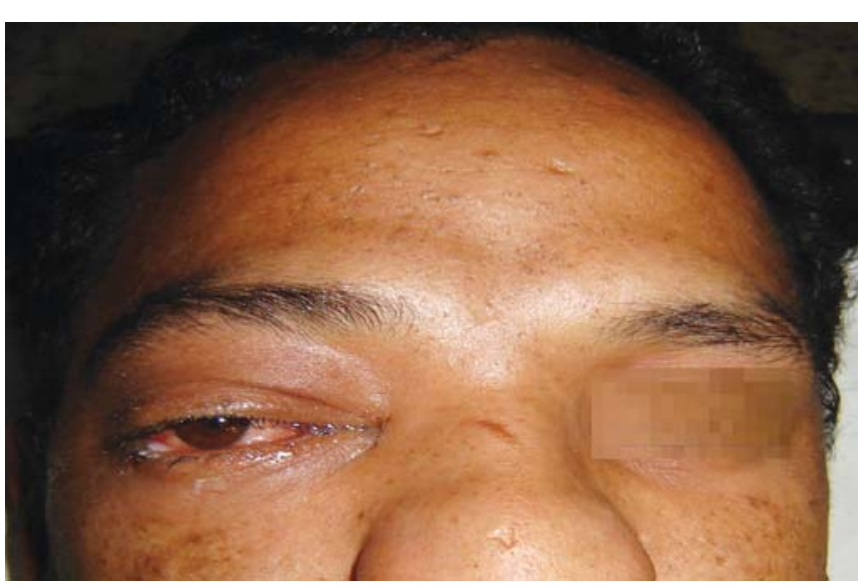

Fig. 1: Preoperative photograph showing chemosis and lateral proptosis of right eye

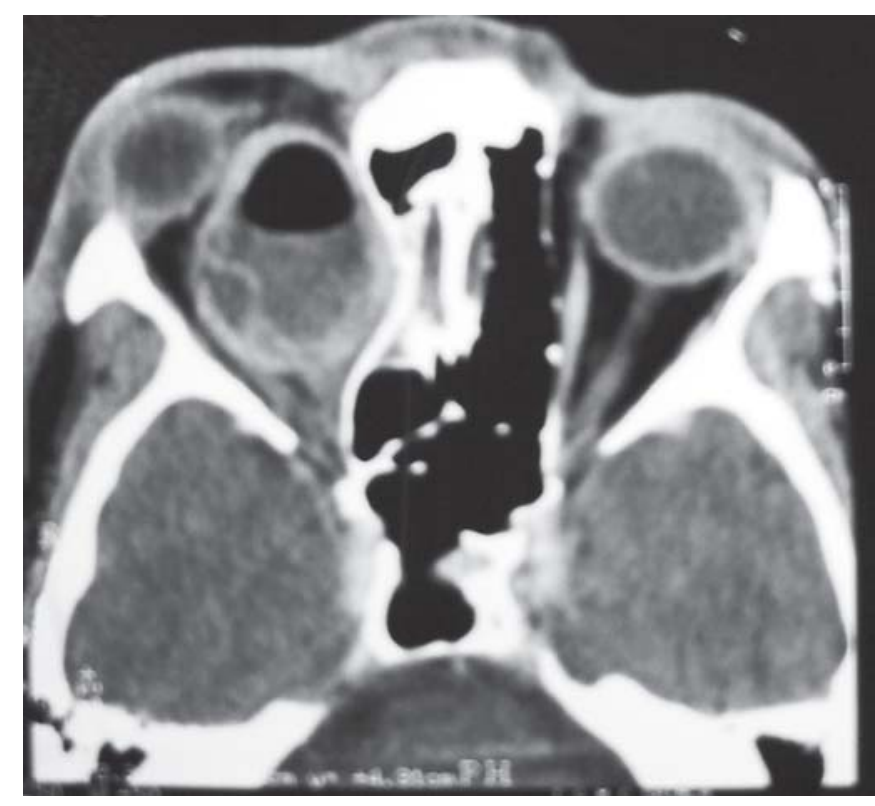

Fig. 2: Contrast enhanced CT scan showing well-formed retro-orbital abscess

3 days. She had fever for last 1 week and no other significant contributory history. General and systemic examination was normal. There was periorbital edema, proptosis with restricted ocular movements. Intraocular pressure and fundus were normal and she could count fingers at 6 meters. Nasal examination showed mucoid discharge with tender left maxillary and frontal sinus. She was started on systemic antibiotics and anti-inflammatory drugs. HRCT of nose and PNS showed maxillary and ethmoid sinusitis with cellulites of retro-orbital compartment. TNES was done, and $2 \mathrm{ml}$ of thick pus was drained. Within next 5 days, ocular movements returned to normal and patient discharged on 6th postoperative day.

\section{Case 3}

A 37-year-old male presented with decreased vision, inability to open eye, and diplopia after sustaining trauma

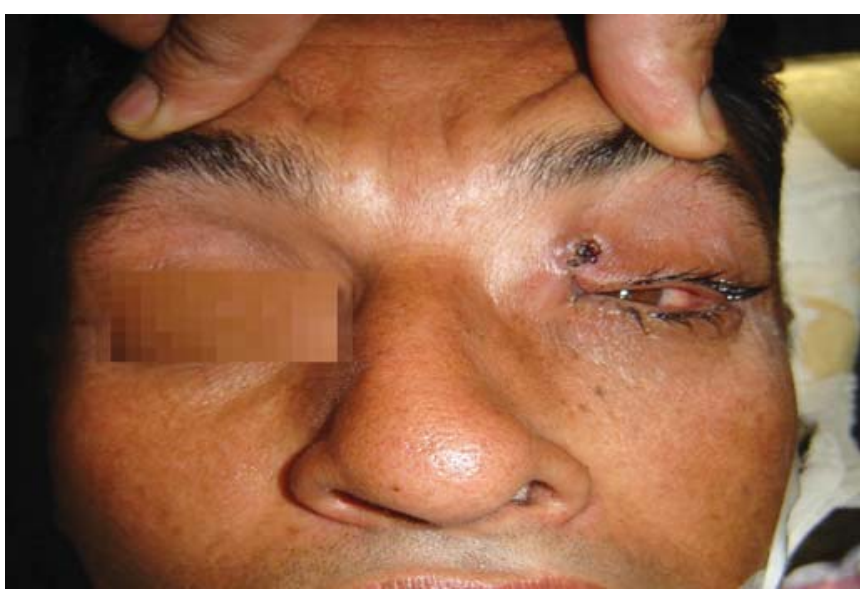

Fig. 3: Preoperative photograph of case 3 showing external injury on left eye with chemosis and proptosis

in left eye 2 weeks back (Fig. 3). Patient consulted an ophthalmologist in a district hospital and stone pieces were removed under local anesthesia. There was no other significant history. Local examination found firm-hard swelling in left medial canthal area. Ocular movements were absent medially and decreased laterally. Pupil and fundus were normal. Visual acuity was 6/36 in left eye and 6/6 in right eye. CT orbit showed fluid collection in retro-orbital area and TNES drainage was done. About $3 \mathrm{ml}$ of pus was drained. Visual acuity improved to $6 / 9$ on third postoperative day but ocular movements were still restricted. Repeat highresolution CT scan of nose and PNS showed displaced fracture of ethmoid which was reduced by external open approach. Ocular movements improved within 3 days and patient was discharged.

\section{RESULTS}

Three patients had retro-orbital abscess and acute vision impairment. They were managed by transnasal endoscopic surgical drainage. All patients showed vision improvement within 72 hours postoperatively.

\section{DISCUSSION}

Sinusitis, dental infection, penetrating trauma, and skin infection are common causes of orbital cellulitis. However, sinusitis is the most common cause of orbital complications. ${ }^{5}$ It can affect all age groups but maxillary and ethmoid sinusitis commonly involves pediatric age group. ${ }^{6}$

Sinusitis causes orbital complications by direct extension of infection through a natural bony dehiscence, local thrombophlebitis, or thromboemboli along the valve-less venous system. ${ }^{5}$ Subperiosteal orbital abscess (SPOA) is the most common orbital complication of sinusitis ${ }^{4}$ and managed conservatively ${ }^{7-9}$ or with TNES.,6,10-15

Retro-orbital abscess (ROA) has propensity for permanent eye damage and intracranial complications. ${ }^{11,12,14,15}$ All the 
cases with orbital complications should be subjected to detailed local and ophthalmic examination with supplementation with CT scan. ${ }^{3-6,10-15}$ Optic disk edema, visual loss or presence of abscess on CT scan needs urgent surgical intervention.

ROA is primarily managed by surgery through external approach, and subconjuctival approach is preferred. Now, SPOA is primarily treated by TNES but there are very few reports of TNES in ROA. ${ }^{3,4}$ Gavriel et al. ${ }^{4}$ presented three cases diagnosed as SPOA on CT scan but found IOA during ESS. They advocated for complete removal of lamina papyracea even in cases of SPOA. They further advised incision of periorbita and gentle application of external orbital pressure looking out ROA. We removed whole of the lamina papyracea similar to the Gavriel et $\mathrm{al}^{4}$ technique but our main objective was decompression of the orbit to prevent further vision loss, and secondly to remove the sinus pathology simultaneously.

Orbital decompression is commonly performed in Grave's ophthalmopathy, and retro-orbital pressure symptom due to cellulitis, abscess, hematoma or tumor. As endoscopic orbital decompression is gaining popularity in Grave's disease, its use in ROA should also be preferred due to better localization and cosmetic results.

Role of endoscopic drainage in medially located abscess needs large sample study as TNES thought to have limited role in superior-lateral orbital abscess, and external approach is preferred. ${ }^{14}$

\section{CONCLUSION}

Transnasal endoscopic surgery is preferred in subperiosteal orbital abscess but its role in retro-orbital abscess is still evolving. We treated three cases of retro-orbital abscess with transnasal endoscopic surgery, and found endoscopy a useful tool in such cases. However, role of transnasal endoscopic surgery in superior-lateral located retro-orbital abscess needs further evaluation.

\section{REFERENCES}

1. Michel O, Bresgen K, Rüssmann W, Thumfart WF, Stennert E. Endoscopically-controlled endonasal orbital decompression in malignant exophthalmos. Laryngorhinootologie 1991;70(12): 656-62.

2. Kennedy DW, Goodstein ML, Miller NR, Zinreich SJ. Endoscopic transnasal orbital decompression. Arch Otolaryngol Head Neck Surg 1990;116(3):275-82.

3. Wolf SR, Gode U, Hosemann W. Endonasal endoscopic surgery for rhinogen intraorbital abscess: A report of six cases. Laryngoscope 1996;106:105-10.

4. Gavriel H, Kessler A, Eviatar E. Management implications of diagnosing orbital abscess as subperiosteal orbital abscess. Rhinology 2010;48:90-94.
5. Rahbar R, Robson CD, Petersen RA, DiCanzio J, Rosbe KW, McGill TJ, Healy GB. Management of orbital subperiosteal abscess in children. Arch Otolaryngol Head Neck Surg 2001;127(3):281-86

6. Sciarretta V, Macrì G, Farneti P, Tenti G, Bordonaro C, Pasquini E. Endoscopic surgery for the treatment of pediatric subperiosteal orbital abscess: A report of 10 cases. Int J Pediatr Otorhinolaryngol 2009;73(12):1669-72.

7. Harris GJ. Subperiosteal abscess of the orbit. Age as a factor in the bacteriology and response to treatment. Ophthalmology 1994;101(3):585-95.

8. Garcia GH, Harris GJ. Criteria for nonsurgical management of subperiosteal abscess of the orbit: Analysis of outcomes 1988 to 1998. Ophthalmology 2000;107(8):1454-56.

9. Brown CL, Graham SM, Griffin MC, Smith RJ, Carter KD, Nerad JA, Bauman NM. Pediatric medial subperiosteal orbital abscess: Medical management where possible. Am J Rhinol 2004;18(5):321-27.

10. Deutsch E, Eilon A, Hevron I, Hurvitz H, Blinder G. Functional endoscopic sinus surgery of orbital subperiosteal abscess in children. Int J Pediatr Otorhinolaryngol 1996;34(1-2):181-90.

11. Frohelich P, Pransky SM, Fontaine P, Stearns G, Morgon A. Minimal endoscopic approach to subperiosteal orbital abscess. Arch Otolaryngol Head Neck Surg 1997;123:280-82.

12. Bhargava D, Sankhla D, Ganesan A, Chand P. Endoscopic sinus surgery for orbital subperiosteal abscess secondary to sinusitis. Rhinology 2001;39(3):151-55.

13. Noordzij JP, Harrison SE, Mason JC, Hashisaki GT, Reibel JF, Gross CW. Pitfalls in the endoscopic drainage of subperiosteal orbital abscesses secondary to sinusitis. Am J Rhinol 2002; 16(2):97-101.

14. Tanna N, Preciado DA, Clary MS, Choi SS. Surgical treatment of subperiosteal orbital abscess. Arch Otolaryngol Head Neck Surg 2008;134(7):764-67.

15. Migirov L, Yakirevitch A, Bedrin L, Wolf M. Endoscopic sinus surgery for medial orbital subperiosteal abscess in children. $\mathrm{J}$ Otolaryngol Head Neck Surg 2009;38(4):504-08.

\section{ABOUT THE AUTHORS}

\section{JS Thakur (Corresponding Author)}

Assistant Professor, Department of Otolaryngology and Head and Neck Surgery, Indira Gandhi Medical College, Shimla-171001, Himachal Pradesh, India, Fax: 91-177-2800224, e-mail: anujagdeep@yahoo.co.in j.s.thakur@hotmail.com

\section{NK Mohindroo}

Professor and Head, Department of Otolaryngology and Head and Neck Surgery, Indira Gandhi Medical College, Shimla, Himachal Pradesh, India

\section{DR Sharma}

Professor, Department of Otolaryngology and Head and Neck Surgery Indira Gandhi Medical College, Shimla, Himachal Pradesh, India

\section{Ripudaman Arora}

Senior Resident, Department of Otolaryngology and Head and Neck Surgery, Government Medical College, Chandigarh, India 